\title{
GAS MASS-FLOW METERS: PRINCIPLES AND APPLICATIONS
}

\author{
Manuel Arlindo Amador de Matos`, Viviana da Silva Ferreira \\ University of Aveiro, Department of Environment and Planning, Campus Universitário, 3810-193, Aveiro, Portugal
}

\begin{abstract}
Gas mass-flow meters (GMFM) for original equipment manufacturers (OEM) applications are presently found in a relatively easy and cheap way. GMFM may be applied in a number of different situations but technical information concerning its principles of measurement and applications are still misleading.

In this paper, the principles of GMFM measurement are discussed and the operating parameters are clarified. A concept of gas mass-flow response factor is introduced and further used in a model for gas mass-flow measurement that is suitable to any gas mixture of known composition.

In addition, a model for the application of GMFM to dynamic volumetric methods of dilution is presented and generalized.
\end{abstract}

Keywords

Gas mass-flow meters, dynamic volumetric methods, response factor, calibration, gas mixtures, gas sensors

\section{1 - INTRODUCTION}

Gas mass-flow meters (GMFM) are used on the metrology of gas flow. The core of the actual GMFM sensors is the thermal sensor consisting in a heated resistance which value depends on temperature. In fact, the temperature of the resistance varies due the neighbouring gas flow that withdraws heat from the device in any proportional way to the gas flow rate.

GMFM sensors have very significant advantages over the traditional gas measurement systems based on classic volumetric flow meters (rotameters, wet and dry meters, venturi meters, orifice plate meters, etc.), because they produce an output signal that can be used in automatic measurement and control applications.

A special type of integrated gas mass-flow meters and control valves are known as thermal mass-flow controllers (GMFC). This technology operates on the basis of a sequence of heated points along the gas path flow and a self-regulating Wheatstone bridge (see [1]), and has been extensively used in gas flow measurement and control, but has the disadvantage of being expensive.

Some common applications of the hot wire technology include: (a) the enclosed mass-flow sensors used in air measurement on diesel and gasoline motors; (b) the anemometers used in open-air velocity measurements; (c) the thermal conductivity detectors (TCD) used in chromatographic measurements.

\footnotetext{
"Corresponding author. Tel.: +351 234370 200; fax: +351 234429290

E-mail address: amatos@ua.pt
} 
More recently, new electronic devices have been developed for gas flow measurement applications, based on heated sensor elements over surfaces. Micro-machining technology enables small-size and high-performance GMFM electronic sensors. This technology of flow sensors has good mechanical strength and may include additional integrated functions, like temperature compensation or linearity. The interest of these GMFM sensors lies in the fact that they are actually cheaper, versatile and even more accessible than the referred classic flow meters.

This work describes some useful models related to use and application of these last GMFM sensors. Commercial micro-machined technology GMFM sensors, with a gas flow throughput ranging from 1 litre of air per minute (Lpm) to about $20 \mathrm{Lpm}$, were used as testing devices.

\section{2 - MODELING GAS MASS-FLOW METERS}

\section{1 - Principles of measurement}

The principle of gas mass-flow measurement (GMFM) is based on the fact that the output voltage of the sensor element is related to the rate of heat transfer between the sensor and the gas. The rate of heat transfer depends mainly on the gas flow rate (or velocity), as the main effect, but also on the gas composition, which influences its thermo-physical properties, like thermal conductivity and thermal diffusivity.

The technology of micro-bridge silicon gas mass-flow sensors uses thin films of heat resistant of 2 or 3 micrometers of dielectric material, special micro-machined support and a set of electric resistances. The resistances are suspended in cavities, which provide thermal insulation. As the heat is transferred from one resistance to the following through the gas flow, the unbalance of the resistance is proportional to the gas mass-flow. The small size of these devices leads to a high sensitivity and fast response time ( $\leq 3 \mathrm{~ms}$ ) (see [2]).

The technology of these sensors gives an output voltage directly proportional to the massflow rate of gas throughout it. This relation can be established by single calibration in case of low gas flow rate sensors or by dynamic volumetric methods of calibration in case of high gas flow rate sensors.

\section{2 - Single calibration}

The single calibration is the procedure for which a GMFM is subject to different known flow rates of a gas of a given composition.

The single calibration is usually applied to low flow rate sensors and can be established against primary devices such as: wet-gas meter, soap-film bubble burette meter, positive displacement meter or other instruments, depending on the measurement range (see [3]).

In this work, the calibration procedure consists of a set of measurements including the volume (Vol), the time $(\mathrm{t})$ and the sensor output voltage $(\mathrm{V})$.

The volumetric gas flow rate is given by

$$
\mathrm{G}_{\mathrm{v} 1}=\frac{\mathrm{Vol}}{\mathrm{t}}
$$

Additional measurement of the operating temperature $(T)$ and absolute pressure $(P)$ enables to calculate the respective gas mass-flow rate $\left(G_{m 1}\right)$ considering the state equation of ideal gases

$$
P G_{v 1} M_{1}=G_{m 1} R^{*} T
$$

where $M_{1}$ is molar weight of the calibration gas and $R^{*}$ is the perfect law gas constant. The models of regression for the calibration data of the GMFM are arbitrary; the linear form is given by 


$$
\mathrm{G}_{\mathrm{m} 1}=\mathrm{a}_{0}+\mathrm{a}_{1} \mathrm{~V}
$$

but other regression models may be used, for instance like a second degree polynomial

$$
\mathrm{G}_{\mathrm{m} 1}=\mathrm{a}_{0}+\mathrm{a}_{1} \mathrm{~V}+\mathrm{a}_{2} \mathrm{~V}^{2}
$$

\section{3 - Gas mass-flow response factors}

It can be verified that the GMFM output voltage depends not only on the mass-flow rate (or volumetric-flow rate) of gas but also on the composition of the gas, since the output voltage of the sensor depends on its thermo-physical properties. Gas properties depend on the operating temperature and pressure and the chemical composition. Hence, in case of mixtures, the output voltage of a given GMFM depends also on the mole fraction of each gas species in the mixture. In order to account for the effect of the gas composition, specific gas mass-flow response factors must be considered, providing an opportunity to generalize the application of GMFM.

Conversely, for a given GMFM, by using the response factors for each of the evolved gas species, it is possible to determine the gas mass-flow rate from the sensor output voltage and the chemical composition of the gas mixture.

The specific response factor for a given gas species cannot be established in an absolute way, but instead, it must be calculated in order to a reference gas, usually nitrogen. Gas mass-flow response factors must be established experimentally and can be specific for a given GMFM technology.

\subsection{1 - Determination of single gas mass-flow response factors}

For a given GMFM, the response factor of the ith gas relative to a reference gas, hereafter nitrogen $\left(\mathrm{f}_{\mathrm{i}, \mathrm{N} 2}\right)$, can be calculated from a single calibration procedure applied both for ith gas and nitrogen $\left(\mathrm{N}_{2}\right)$. The mass-flow rate of the ith gas is computed by

$$
\mathrm{G}_{\mathrm{mi}}=\mathrm{G}_{\mathrm{mN} 2} \frac{\mathrm{f}_{\mathrm{i}, \mathrm{N} 2}}{\mathrm{f}_{\mathrm{N} 2, \mathrm{~N} 2}}
$$

If, by convention, the response factor of the sensor to nitrogen $\left(f_{\mathrm{N} 2}, \mathrm{~N}_{2}\right)$ is arbitrarily fixed as unit $\left(f_{\mathrm{N} 2, \mathrm{~N} 2}=1\right)$, then, for the same output voltage $(\mathrm{V})$ of the GMFM, the response factor of the single ith gas in relation to nitrogen $\left(f_{i, N}\right)$ can be established as the ratio between the massflow rate of ith pure gas to the mass-flow rate of pure nitrogen $\left(\mathrm{N}_{2}\right)$

$$
f_{i, N 2}=\frac{G_{m i}}{G_{m N 2}}
$$

In practice, it can be used reliable regression mass-flow models for the GMFM (like anyone presented in sec.2.2), either for the ith gas and for $\mathrm{N}_{2}$; after, appropriate output voltage values can be selected in the range of measurement of the sensor and the mass-flow rate of pure gas $i\left(G_{m i}\right)$ and of nitrogen $\left(G_{m N 2}\right)$ are computed. Then, mass-flow response factor of a pure gas i relative to nitrogen $\left(\mathrm{f}_{\mathrm{i}, \mathrm{N} 2}\right)$ must be calculated from Eq.6.

\subsection{2 - The mass-flow rate of a single gas}

The measurement of the mass-flow rate $\left(G_{m k}\right)$ can be done from the regression model got from the single calibration procedure with the kth gas, using the expressions presented in sec.2.2.

However it is possible to get the same objective using the regression mass-flow model of the GMFM established from the ith gas (like $N_{2}$ ), since it must be taken into account the response factors of ith and kth gases, using 


$$
G_{m k}=G_{m i} \frac{f_{k, N 2}}{f_{i, N 2}}
$$

\subsection{3 - The mass-flow rate of a gas mixture relative to nitrogen}

To determine the mass-flow rate of a given gas mixture $\left(G_{m M}\right)$ it is certainly necessary to consider the overall response factor of the own gas mixture. This overall response factor of the gas mixture depends on the mole fraction of each component in the mixture $\left(\mathrm{y}_{\mathrm{i}}\right)$ and also on the specific response factors of each component present in the mixture $\left(\mathrm{f}_{\mathrm{i}, \mathrm{N} 2}\right)$ with reference to nitrogen, as defined above.

Thus, for a gas mixture of known composition $y_{i}$ and computed nitrogen mass-flow rate reference gas $\left(\mathrm{G}_{\mathrm{mN} 2}\right)$ from the output voltage of the sensor and its regression model for nitrogen reference gas, then

$$
\mathrm{G}_{\mathrm{mN} 2}=\sum \mathrm{G}_{\mathrm{mi}, \mathrm{N} 2}
$$

where the ith component of the gas mixture can be written in terms of its response factor by

$$
\mathrm{G}_{\mathrm{mi}, \mathrm{N} 2}=\mathrm{G}_{\mathrm{mi}} \frac{1}{\mathrm{f}_{\mathrm{i}, \mathrm{N} 2}}
$$

but since

$$
\mathrm{G}_{\mathrm{mi}}=\mathrm{G}_{\mathrm{mM}} \mathrm{w}_{\mathrm{i}}
$$

and the mass fraction of the ith gas component of the mixture $\left(w_{i}\right)$ is related with its molar fraction $\left(\mathrm{y}_{\mathrm{i}}\right)$ by

$$
w_{i}=\frac{y_{i} M_{i}}{\sum y_{i} M_{i}}
$$

then

$$
G_{m i}=G_{m M} \frac{y_{i} M_{i}}{\sum y_{i} M_{i}}
$$

Taking into account the molar weight of the gas mixture

$$
\mathrm{M}_{\mathrm{G}}=\sum \mathrm{y}_{\mathrm{i}} \mathrm{M}_{\mathrm{i}}
$$

therefore, the Eq.8 can be written as

$$
G_{m N 2}=G_{m M} \frac{1}{M_{G}} \sum\left(\frac{y_{i} M_{i}}{f_{i, N 2}}\right)
$$

where the overall response factor of the gas mixture with reference to nitrogen $\left(\Phi_{\mathrm{M}, \mathrm{N} 2}\right)$ can be done as

$$
\Phi_{\mathrm{M}, \mathrm{N} 2}=\frac{\mathrm{M}_{\mathrm{G}}}{\sum\left(\frac{\mathrm{y}_{\mathrm{i}} \mathrm{M}_{\mathrm{i}}}{\mathrm{f}_{\mathrm{i}, \mathrm{N} 2}}\right)}
$$

therefore, the gas mass-flow of the mixture $\left(G_{m M}\right)$ can be computed by

$$
\mathrm{G}_{\mathrm{mM}}=\mathrm{G}_{\mathrm{mN} 2} \Phi_{\mathrm{M}, \mathrm{N} 2}
$$


2.3.4 - Mass-flow rate of a mixture relative to an arbitrary calibration gas

In a situation when it is known the calibration data for an arbitrary single gas (or mixture) k, the mass-flow of the gas sensor can be calculated as

$$
\mathrm{G}_{\mathrm{mM}}=\mathrm{G}_{\mathrm{mk}} \Phi_{\mathrm{Mk}}
$$

where $G_{m k}$ is the calculated mass-flow rate from the observed output voltage of the GMFM and the gas mixture response factor is computed from

$$
\Phi_{M k}=\sum \frac{f_{i, k}}{w_{i}}=\sum \frac{f_{i, N 2}}{w_{i} f_{k, N 2}}=\frac{1}{f_{k, N 2}} \frac{M_{G}}{\sum\left(\frac{y_{i} M_{i}}{f_{i, N 2}}\right)}=\frac{1}{f_{k, N 2}} \Phi_{M, N 2}
$$

as can be derived without difficulty.

\section{4 - A model for dilution using dynamic volumetric methods}

Considering a parallel arrangement of $M-1$ streams of known gas mass-flows $\left(G_{m j}, j=1,2, . . M-\right.$ 1) and known composition of $\mathrm{N}$ gaseous components $\left(\mathrm{y}_{\mathrm{ij}}, \mathrm{i}=1,2, . . \mathrm{N}\right)$, as shown in Fig. 1 ,

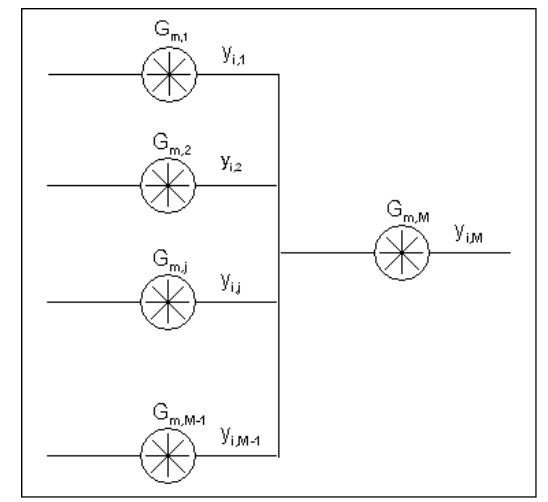

Fig. 1 - Notation of the dilution model by the dynamic volumetric method

then, the overall mass-flow of the resulting gas mixture $(M)$ is given by

$$
G_{m M}=\sum G_{m j}, j=1,2, . . M-1
$$

To each ith gas component $(i=1,2, . . N)$ of the Mth mixture, the mass-flow balance can be calculated as

$$
\mathrm{G}_{\mathrm{miM}}=\sum \mathrm{G}_{\mathrm{mij}}
$$

or, in a molar basis, as

$$
\frac{G_{m M} y_{i M}}{\sum y_{i M} M_{i}}=\sum\left(\frac{G_{m j} y_{i j}}{\sum y_{i j} M_{i}}\right)
$$

where $y_{i m}$ is the molar fraction of the ith gaseous component of the Mth mixture, and

$$
\sum \mathrm{y}_{\mathrm{iM}}=1
$$

The composition of the resulting mixture $(\mathrm{M})$ can be established from Eq.21, as 


$$
\frac{\mathrm{y}_{\mathrm{iM}}}{\sum \mathrm{y}_{\mathrm{iM}} \mathrm{M}_{\mathrm{i}}}=\frac{1}{\mathrm{G}_{\mathrm{mM}}} \sum\left(\frac{\mathrm{G}_{\mathrm{mj}} \mathrm{y}_{\mathrm{ij}}}{\sum \mathrm{y}_{\mathrm{ij}} \mathrm{M}_{\mathrm{i}}}\right)
$$

where the second member is known (composition and mass-flow), and can be written as

$$
b_{i}=\frac{1}{\sum G_{m j}} \sum\left(\frac{G_{m j} y_{i j}}{\sum y_{i j} M_{i}}\right)
$$

Finally, for the ith gas component of the mixture M, the Eq.23 can be written as

$$
\sum \mathrm{y}_{\mathrm{iM}} \mathrm{M}_{\mathrm{i}}-\frac{\mathrm{y}_{\mathrm{iM}}}{\mathrm{b}_{\mathrm{i}}}=0
$$

Rewriting the last equation on a matrix format, it results a linear system of $\mathrm{NxN}$ equations of $\mathrm{N}$ unknowns $\left(\mathrm{y}_{\mathrm{im}}\right)$, given by

$$
\left[\begin{array}{ccccc}
\left(\mathrm{M}_{1}-\frac{1}{\mathrm{~b}_{1}}\right) & \mathrm{M}_{2} & \ldots & \mathrm{M}_{\mathrm{N}-1} & \mathrm{M}_{\mathrm{N}} \\
\mathrm{M}_{1} & \left(\mathrm{M}_{2}-\frac{1}{\mathrm{~b}_{2}}\right) & \ldots & \mathrm{M}_{\mathrm{N}-1} & \mathrm{M}_{\mathrm{N}} \\
\ldots & \ldots & \ldots & \ldots & \ldots \\
\mathrm{M}_{1} & \mathrm{M}_{2} & \ldots & \left(\mathrm{M}_{\mathrm{N}-1}-\frac{1}{\mathrm{~b}_{\mathrm{N}-1}}\right) & \mathrm{M}_{\mathrm{N}} \\
1 & 1 & \ldots & 1 & 1
\end{array}\right]\left[\begin{array}{c}
\mathrm{y}_{1 \mathrm{M}} \\
\mathrm{y}_{2 \mathrm{M}} \\
\ldots \\
\mathrm{y}_{\mathrm{N}-1, \mathrm{M}} \\
\mathrm{y}_{\mathrm{N}, \mathrm{M}}
\end{array}\right]=\left[\begin{array}{c}
0 \\
0 \\
\ldots \\
0 \\
1
\end{array}\right]
$$

where the last line of the matrix is the equation of the conservation law of species given by the Eq.22, which can be solved by the classic matrix methods, in order to give the molar composition of the Mth gas mixture $\left(\mathrm{y}_{\mathrm{iM}}\right)$.

\section{5 - Calibration of gas sensors using the dynamic volumetric method}

The model for dilution using the dynamic volumetric method has application on the calibration of gas sensors (see also [3]) and to evaluate the output voltage characteristics of the sensors (namely the linearity) for different known concentrations of the active component, prepared from different gas flows of the active component and/or any dilution gas.

For instance, considering the simple situation of a gas mixture prepared from two known gas mass-flows $\left(G_{\mathrm{m} 1}\right.$ and $\left.G_{\mathrm{m} 2}\right)$ and pure gases of known composition $\left(\mathrm{y}_{\mathrm{N} 2,1}=1, \mathrm{y}_{\mathrm{CO} 2,1}=0\right.$ and $\left.\mathrm{y}_{\mathrm{N} 2,2}=0, \mathrm{y}_{\mathrm{CO}, 2}=1\right)(\mathrm{M}=3, \mathrm{~N}=2)$, then the application of the model presented here gives

$$
b_{\mathrm{N} 2}=\frac{1}{G_{m 1}+G_{m 2}}\left(\frac{G_{m 1} y_{N 2,1}}{M_{N 2}}+\frac{G_{m 2} y_{N 2,2}}{M_{\mathrm{CO} 2}}\right)
$$

and

$$
\left\{\begin{array}{l}
\left(\mathrm{M}_{\mathrm{N} 2}-\frac{1}{\mathrm{~b}_{\mathrm{N} 2}}\right) \mathrm{y}_{\mathrm{N} 2, \mathrm{M}}+\mathrm{M}_{\mathrm{CO} 2} \mathrm{y}_{\mathrm{CO} 2, \mathrm{M}}=0 \\
\mathrm{y}_{\mathrm{N} 2, \mathrm{M}}+\mathrm{y}_{\mathrm{CO} 2, \mathrm{M}}=1
\end{array}\right\}
$$

whose solution is the composition of the gas mixture $M\left(y_{\mathrm{N} 2, \mathrm{M},} \mathrm{y}_{\mathrm{CO} 2, \mathrm{M}}\right)$ and $\mathrm{G}_{\mathrm{mM}}=\mathrm{G}_{\mathrm{m} 1}+\mathrm{G}_{\mathrm{m} 2}$. 


\section{6 - Calibration of gas flow sensors using the dynamic volumetric method}

Difficulties with GMFM single calibration can be found with large flow GMFM, because there are not such calibration instruments. In this case, it can be possible to use the referred model for dilution using dynamic volumetric methods applied to the calibration of gas flow sensors. In fact, from the exposed model, it was concluded that it must be possible to calculate an unknown gas mass-flow $\left(G_{m 2}\right)$, of known composition $\left(y_{i 2}\right)$, from a known gas mass-flow $\left(G_{m 1}\right)$ of known composition $\left(\mathrm{y}_{\mathrm{i} 1}\right)$ and of the measurement of only one arbitrary component of the final mixture $\left(y_{\mathrm{iM}}\right)$.

In this work a recurrent calculation method was developed using the unknown gas mass-flow as a pivot variable, where through an initial numeric procedure of generation of estimates, followed by the bisection numeric procedure, it was possible to find the solution successfully, until a small deviation between successive estimates should be found.

\section{3 - MATERIAL AND METHODS}

The application of the present model was tested using some commercial GMFM sensors, composition sensors and gases.

The calibration system of the GMFM was done with a wet-gas meter (rotating drum 0.5 L.rot $^{-}$ ${ }^{1}$ ); simultaneously the temperature of the water was measured with a $\mathrm{K}$ thermocouple and of the atmospheric pressure with a barometric sensor (Vaisala, mod.610B).

Some pure gases $\left(\mathrm{N}_{2}, \mathrm{O}_{2}, \mathrm{Ar}, \mathrm{CO}_{2}\right)$ and mixtures were tested (AirR as pure air manufactured $\mathrm{y}_{\mathrm{O} 2}=0.21, \mathrm{y}_{\mathrm{N} 2}=0.79$ and AirS as dried compressed air: AirS: $\mathrm{y}_{\mathrm{O} 2}=0.2095, \mathrm{y}_{\mathrm{N} 2}=0.78081$, $\mathrm{y}_{\mathrm{Ar}}=0.0093, \mathrm{y}_{\mathrm{CO} 2}=0.00039$ ).

The measurement procedure was carried out with a computer data acquisition and control system. To this effect an extensive programming for the acquisition and treatment of data was developed. More details about the technology, procedures and results can be found in Ferreira [4].

\section{1 - Sensors}

\subsection{1 - Gas mass-flow meters (GMFM)}

The technical characteristics of GMFM sensors that were tested in this work are presented in Table 1.

Table 1 - Manufacturer technical description of the GMFM sensors

\begin{tabular}{ccccccc}
\hline Manufacturer & Model & $\begin{array}{c}\text { Calibration } \\
\text { gas }\end{array}$ & $\begin{array}{c}\text { Maximum } \\
\text { flow rate }\end{array}$ & $\begin{array}{c}\text { Sensor output } \\
\text { range }\end{array}$ & $\begin{array}{c}\text { Temperature } \\
\text { range }\end{array}$ & Linearity \\
\hline \hline Honeywell & AWM5101VN & $\mathrm{N}_{2}$ & $5 \mathrm{Lpm}$ & $1 \mathrm{~V}-5 \mathrm{~V}$ & $-20^{\circ} \mathrm{C} \ldots+70^{\circ} \mathrm{C}$ & linear \\
Honeywell & AWM5104VN & $\mathrm{N}_{2}$ & $20 \mathrm{Lpm}$ & $1 \mathrm{~V}-5 \mathrm{~V}$ & $-20^{\circ} \mathrm{C} \ldots+70^{\circ} \mathrm{C}$ & linear \\
Omron & D6F-01A1-110 & Air & $1 \mathrm{Lpm}$ & $1 \mathrm{~V}-5 \mathrm{~V}$ & $-10^{\circ} \mathrm{C} \ldots+60^{\circ} \mathrm{C}$ & not linear \\
\hline
\end{tabular}

3.1.2 - Carbon dioxide sensor

For this work, a linear carbon dioxide gas sensor was selected whose characteristics are presented in Table 2.

Table 2 - Manufacturer technical description of the carbon dioxide sensor

\begin{tabular}{cccccc}
\hline Manufacturer & Model & Gas & $\begin{array}{c}\text { Composition range } \\
(\mathrm{v} / \mathrm{v})\end{array}$ & $\begin{array}{c}\text { Sensor output } \\
\text { range }\end{array}$ & Linearity \\
\hline \hline Vaisala & GMP221 & $\mathrm{CO}_{2}$ & $0 \%-20 \%$ & $0 \mathrm{~V}-5 \mathrm{~V}$ & linear \\
\hline
\end{tabular}

where the concentration of carbon dioxide $(\% \mathrm{v} / \mathrm{v})$ can be related with molar fraction of $\mathrm{CO}_{2}$ by 


$$
\mathrm{y}_{\mathrm{CO} 2}=\frac{\mathrm{C}_{\mathrm{CO} 2}}{100}
$$

\section{2 - Procedures of calibration of GMFM}

\subsection{1 - Single calibration}

In the single calibration procedure, the GMFM sensor was arranged in series with the wet gas flow meter calibrator (see Fig. 2). The sensor was tested with different flows $\left(G_{m 1}\right)$ of different gases. For each test, the volume of the calibration gas $\mathrm{Vol}(\mathrm{L})$, the elapsed time $t$ ( $\mathrm{min})$, the GMFM sensor output voltage $(\mathrm{V})$ were registered, as well as the temperature $(\mathrm{K})$ and atmospheric pressure $(\mathrm{Pa})$.

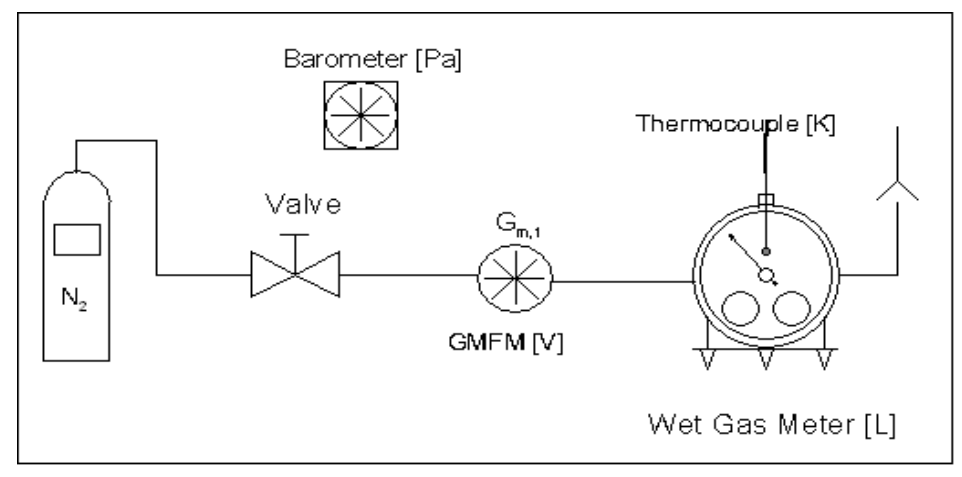

Fig. 2 - Schema of the gas circuit for the single calibration of a GMFM

The mass-flow $\mathrm{G}_{\mathrm{m} 1}\left(\mathrm{~g} \cdot \mathrm{min}^{-1}\right)$ must be calculated and appropriate regression model for fitting the data must be chosen.

\subsection{2 - Calibration by dynamic volumetric methods}

In the dynamic calibration, the GMFM sensor of high capacity to be calibrated was arranged in parallel with one GMFM calibrated, as shown in Fig. 3. The active gas chosen was $\mathrm{CO}_{2}$. The equipment and material necessary include: a previously calibrated $\mathrm{CO}_{2}$ gas sensor, a mixture gas chamber, a cylinder with a known concentration of the active gas $\left(\mathrm{y}_{\mathrm{CO} 2,1}=1.00\right)$, a mass-flow sensor $\left(G_{\mathrm{m} 1}\right)$ previously calibrated by the single method, a dilution gas (AirS: $\left.\left.\mathrm{y}_{\mathrm{O} 2,2}=0.2095, \mathrm{y}_{\mathrm{N} 2,2}=0.78081, \mathrm{y}_{\mathrm{Ar}, 2}=0.0093, \mathrm{y}_{\mathrm{CO}, 2}=0.00039\right)\right)$, and the GMFM of high flow rate to calibrate $\left(\mathrm{G}_{\mathrm{m} 2}\right)$.

It was recorded a table with $\mathrm{CO}_{2}$ mole fraction of the mixture at the outlet $\left(\mathrm{y}_{\mathrm{CO}, \mathrm{M}}\right)$, the gas mass-flow $\mathrm{G}_{\mathrm{m} 1}\left(\mathrm{~g} \cdot \mathrm{min}^{-1}\right)$, and the GMFM sensor output voltage $(\mathrm{V})$ under calibration.

In a first step, the gas mass-flow $G_{m 2}$ is calculated from the model presented in the section 2.6 for each record. Finally, a convenient regression model for fitting the data was chosen. 


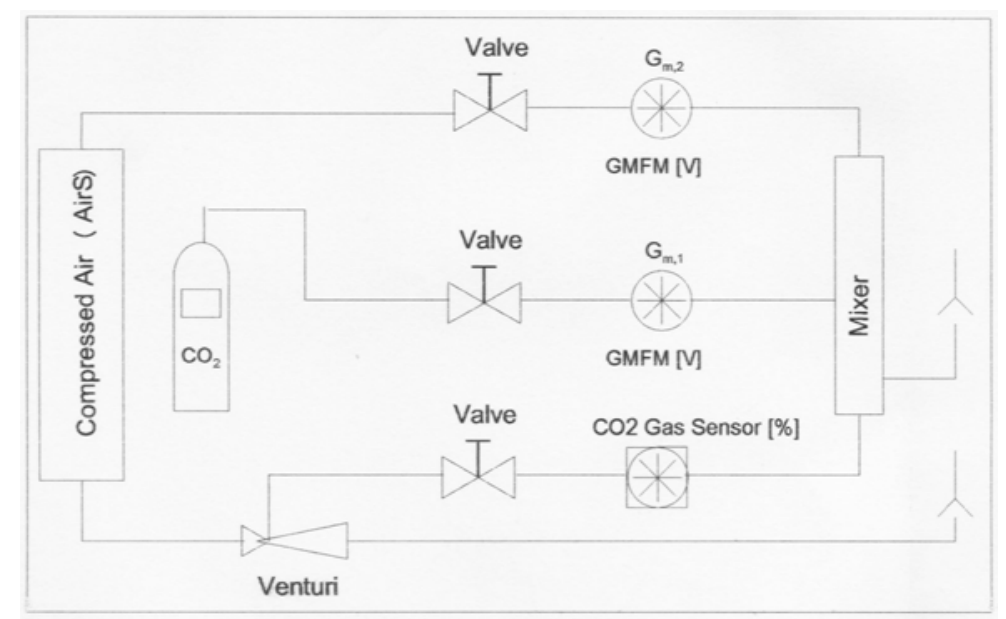

Fig. 3 - Schema of the gas circuit for the calibration of a GMFM by a dynamic volumetric method

\section{3 - Procedures of calibration of $\mathrm{CO}_{2}$ gas sensor}

The evaluation of the characteristics of the carbon dioxide gas sensor referred above was conducted with zero gas (pure nitrogen) and span gas (15\% v/v of carbon dioxide in nitrogen calibration mixture).

For the evaluation of the output voltage characteristics of the carbon dioxide gas sensor, it was used the experimental set shown in Fig. 3. However, in this case, it was used two previously calibrated GMFM sensors by the single calibration procedure described in sec.3.2.1: the GMFM Honeywell model AWM5101VN (0 Lpm to $5 \mathrm{Lpm}$ ) for dilution gas and the GMFM Omron D6F-01A1-110 (0 Lpm to $1 \mathrm{Lpm})$ for pure carbon dioxide gas in a cylinder $\left(\mathrm{y}_{\mathrm{CO}, 1}=1.00\right)$.

\section{4 - RESULTS AND DISCUSSION}

\section{1 - Single calibration of GMFM}

The single calibration method was used to establish the regression model of GMFM Omron (0-1 Lpm) and GMFM Honeywell (0-5 Lpm) sensors, as referred in section 3.3.1. The results for each gas and GMFM can be observed in Fig. 4 and Fig. 5.

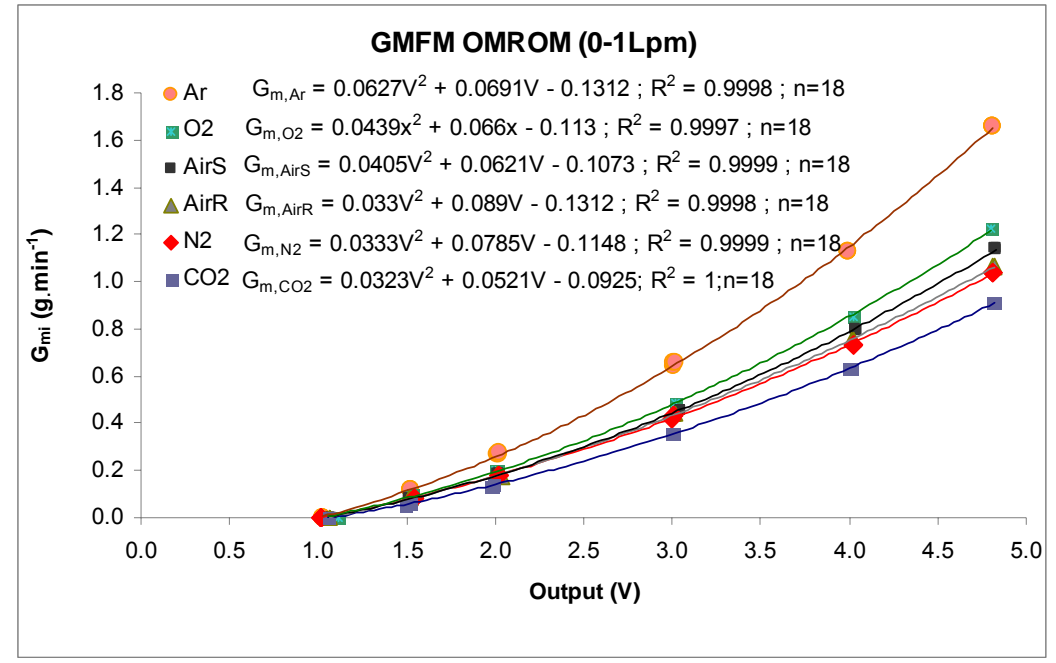


Fig. 4. Single calibration of GMFM Omron (0-1 Lpm) for different gases

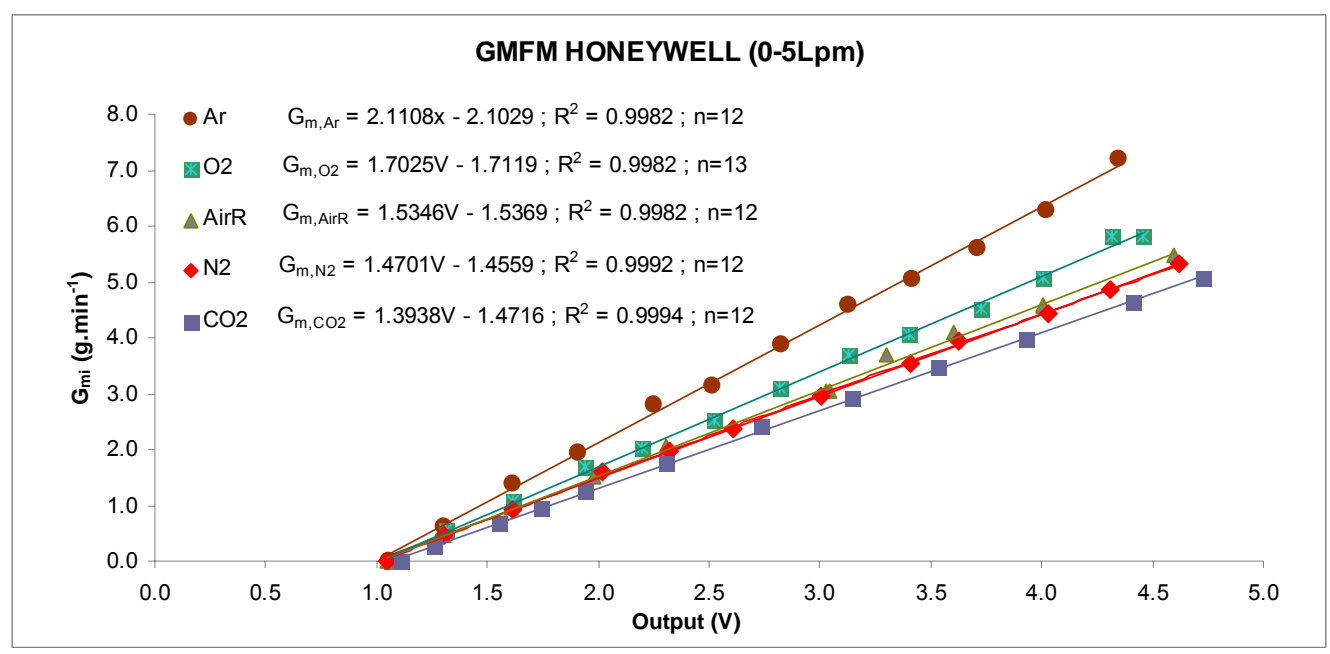

Fig. 5. Single calibration of the GMFM Honeywell (0-5 Lpm) for different gases

The results of the GMFM Omron (0-1 Lpm) for different gases show that the sensor output voltage is not linear with relation to gas mass flow, although it can be represented closely by a polynomial of second degree. Instead, the output voltage of the GMFM Honeywell (0-5 $\mathrm{Lpm}$ ) sensor shows linearity with gas mass-flow. These patterns agree with the manufacturer data sheets.

\section{2 - Calibration of GMFM by a dynamic volumetric method}

A dynamic volumetric method calibration was used to establish the regression model of GMFM Honeywell (0-20 Lpm), as referred in section 3.2.2. The results (15 points) for dried and cleaned compressed air (AirS) can be observed in Fig. 6.

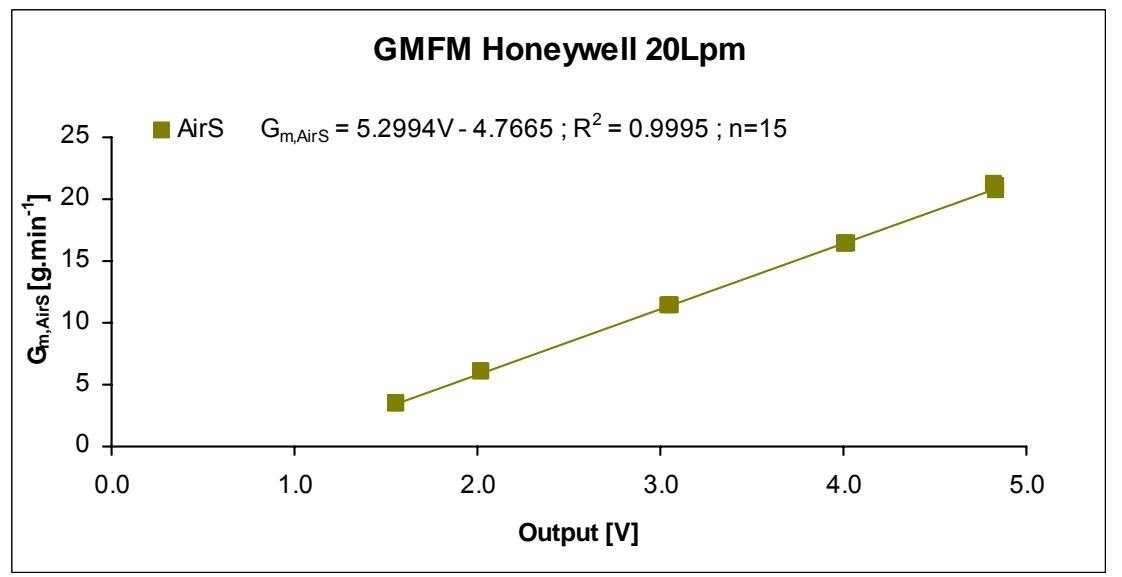

Fig. 6 - Calibration of the GMFM Honeywell (0-20 Lpm) sensor using a dynamic volumetric method with dried air (AirS) 
This procedure doesn't allow the evaluating of very low mass flows (the tracer concentration would exceed the measuring range of the sensor of composition). The results show agreement with the manufacturer data sheet.

\section{3 - Response factors}

Upon analysing the results of the Fig. 4 and Fig. 5, it can be concluded that the GMFM sensors are influenced by the composition of the gas, which means that for the same gas mass-flow rate different output voltage $(\mathrm{V})$ can be observed. The sensitivity of any GMFM occurs in the following order (argon $(\operatorname{Ar})>$ oxygen $\left(\mathrm{O}_{2}\right)>$ dried air (AirS) > synthetic air (AirR) $>$ nitrogen $\left(\mathrm{N}_{2}\right)>$ carbon dioxide $\left(\mathrm{CO}_{2}\right)$ ). This sensitivity can be defined as response factors $\left(f_{i, N 2}\right)$, according to the Eq. 6 and the method presented in sec.2.3. The results can be seen in Fig. 7 and Fig. 8.

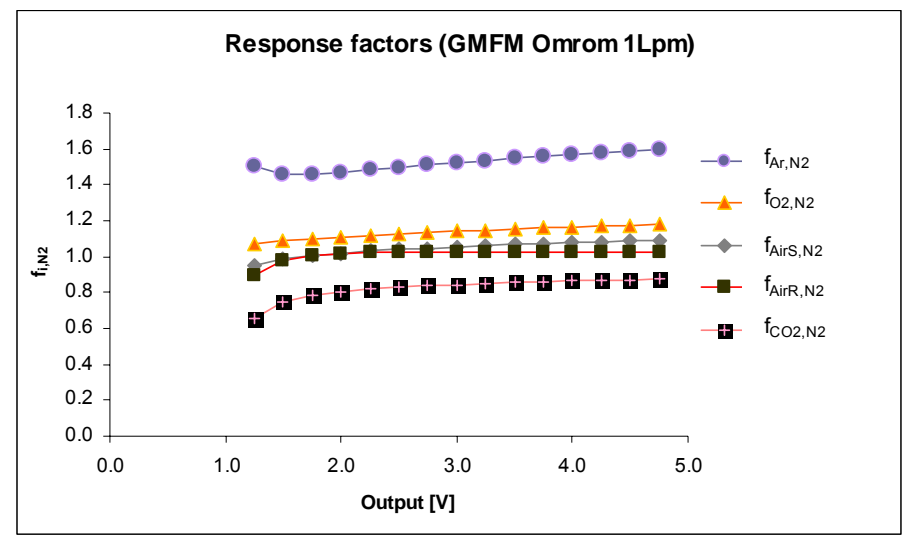

Fig. 7 - Response factors of the GMFM Omron (0-1 Lpm) for some gases

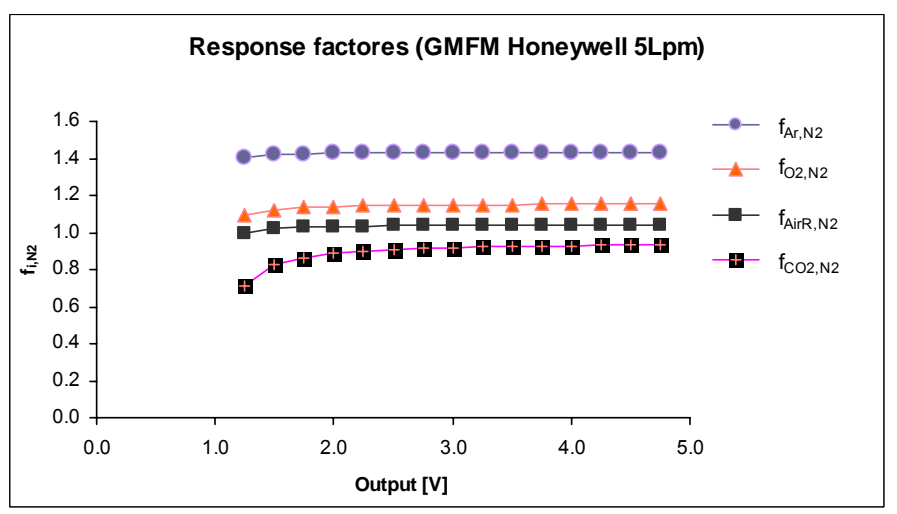

Fig. 8 - Response factors of the GMFM Honeywell (0-5 Lpm) for some gases

In general, the analysis of these results shows a small increase of the response factors with the mass-flow through of the sensor.Then, the gas response factors of the GMFM sensors depend on the gas composition, the flow rate and the sensor manufacturer. However it can be concluded that almost constant values for response factor $\left(\mathrm{f}_{\mathrm{i}, \mathrm{N} 2}\right)$ above the upper $75 \%$ output voltage range of the sensor can be observed, and an average response factor can be calculated, for some gases (see Table 3). On considering the GMFM technology, it is remarkable that the trends of the mean response factors are the same, although it will be advisable the use of gas response factors specific of each GMFM sensor device technology. 
Table 3 - Average response factors for some gases relative to nitrogen

\begin{tabular}{cccccc}
\hline GMFM sensor & $\mathbf{f}_{\text {CO2,N2 }}$ & $\mathbf{f}_{\text {AirR,N2 }}$ & $\mathbf{f}_{\text {O2,N2 }}$ & $\mathbf{f}_{\text {AirS,N2 }}$ & $\mathbf{f}_{\text {Ar,N2 }}$ \\
\hline \hline Omrom 1Lpm & 0.824 & 1.013 & 1.136 & 1.044 & 1.525 \\
Honeywell 5Lpm & 0.894 & 1.034 & 1.143 & - & 1.428 \\
\hline
\end{tabular}

This trend for the response factors of each gas agrees directly with dynamic viscosity, but not with other single thermophysical gas properties like density, thermal conductivity or heat capacty.

\section{4 - Application of response factors to mass-flow measurement}

Considering the gas mixture identified as AirR, and taking into account the pure gas response factors of GMFM in the Fig. 7 and Fig. 8, it was evaluated the response factor done by Eq. 15 labeled as $\Phi_{\text {AirR_mod_A }}$ in Fig. 9 and Fig. 10 for the two GMFM sensors tested.

For comparision purposes, it is shown the specific gas response factors calculated from the calibration data and labed as $\mathrm{f}_{\text {AirR_obs }}$ (see $\mathrm{f}_{\text {AirR,N2 }}$ in Fig. 7 and Fig. 8).

Although it can be concluded from this example that the results agree reasonnably well each other for a given GMFM sensor, it seems that it will be necessary a more extensive research work applied to other gas mixtures in order to evaluate more extensively the presented gas response factor model usefulness to gas mass-flow measurement and to establish its uncertainty.

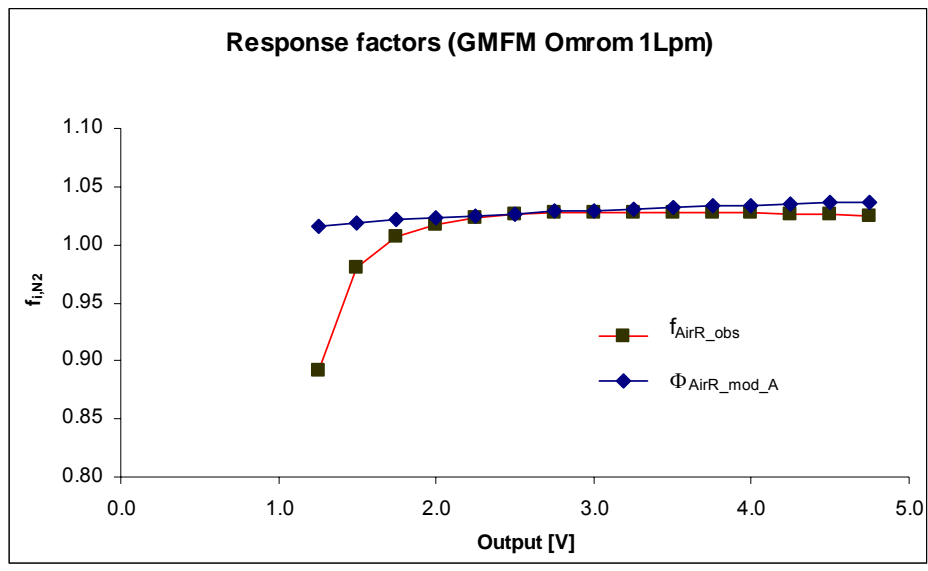

Fig. 9 - Response factors for AirR of the GMFM Omrom (0-1 Lpm)

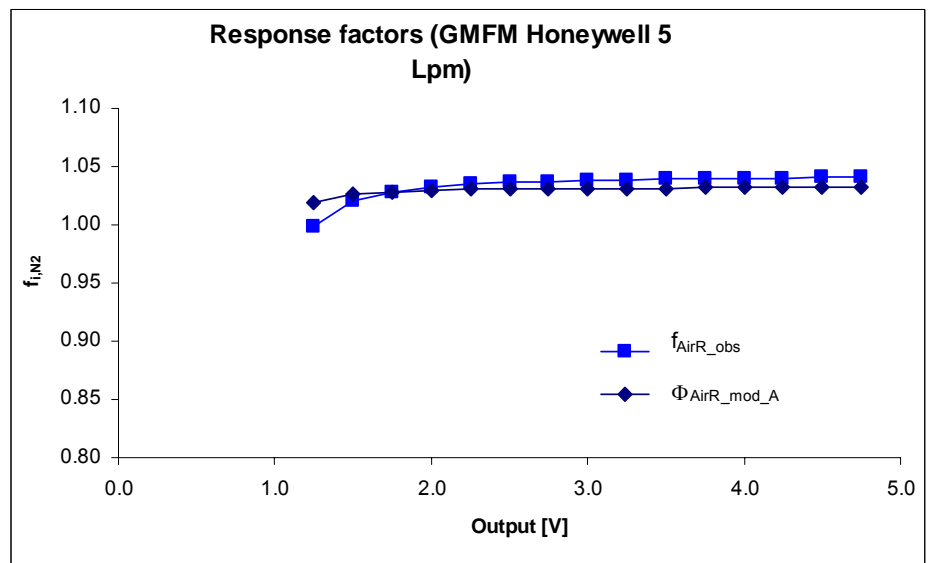


Fig. 10 - Response factors for AirR of the GMFM Honeywell (0-5 Lpm)

\section{5 - Single and dynamic calibration of the carbon dioxide sensor}

The results of the single calibration of the Vaisala $\mathrm{CO}_{2}$ sensor $(0-20 \%)$ obtained with nitrogen (zero gas) and a mixture of $15 \% \mathrm{v} / \mathrm{v}$ of $\mathrm{CO}_{2}$ in nitrogen (span gas) can be found in Fig. 11. The results of the dynamic volumetric method applied to the calibration of $\mathrm{CO}_{2}$ sensor can be seen in Fig. 11, which includes the respective regression model.

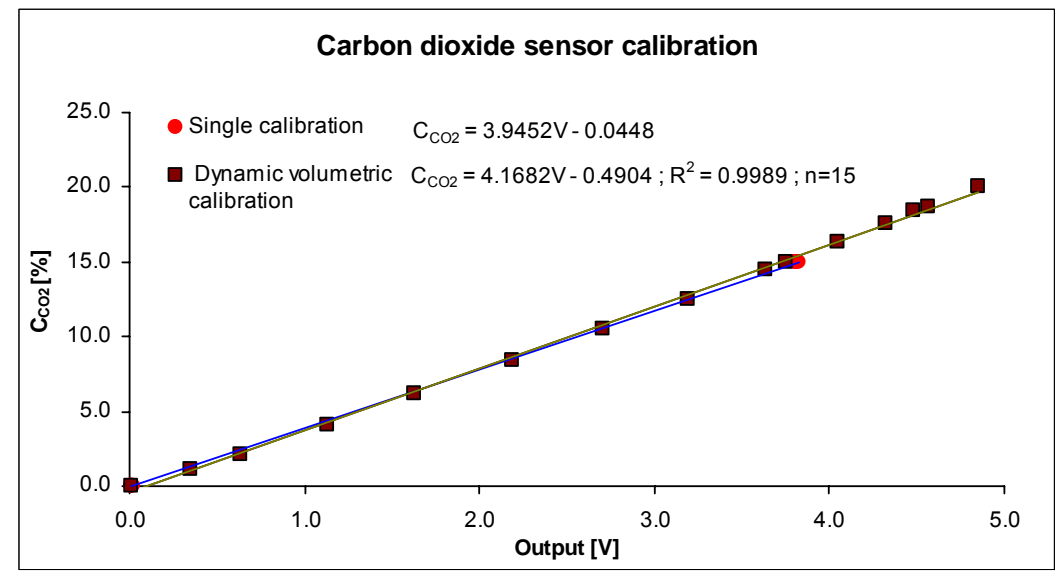

Fig. 11 - Single and dynamic volumetric calibration of the $\mathrm{CO}_{2}$ sensor (0-20\%)

From these results, it can be concluded that the Vaisala $\mathrm{CO}_{2}$ sensor is linear and the dynamic volumetric method of gas dilution presented in this work using GMFM sensors was useful and accurate.

\section{5 - CONCLUSIONS}

A model for dilution using dynamic volumetric methods based on mass balance of gaseous species and calibrated gas mass flow meters was presented in this work. It was concluded that this model is useful and accurate, as it was shown in the calibration of either gas sensors or high throughput gas mass flow meters.

However, it was also shown that gas mass-flow meters output voltage depends on the gasmass flow, but also, to some extent, on the composition of the gas.

A model of response factors of GMFM for pure gaseous species $\left(f_{i, N 2}\right)$ was proposed and values for some gases were obtained. It was found small differences on the response factors between different manufacturers of GMFM technology.

A model of response factors for the application of GMFM to any gas mixture from a given calibration data was developed and positively demonstrated for usefulness and accuracy in a case study. However, a more extensive work is thought necessary in order to establish the uncertainty of this model in current applications. 


\section{NOMENCLATURE}

\begin{tabular}{|c|c|c|}
\hline$a_{0}$ & - Independent term of a regression model of a GMFM & {$\left[\right.$ L. $\left.\min ^{-1}\right]$} \\
\hline$a_{1}$ & - First order term of a regression model of a GMFM & {$\left[\right.$ L. $\left.\min ^{-1} \cdot \mathrm{V}^{-1}\right]$} \\
\hline$a_{2}$ & - Second order term of a regression model of a GMFM & {$\left[\mathrm{L} \cdot \mathrm{min}^{-1} \cdot \mathrm{V}^{-2}\right]$} \\
\hline $\mathrm{C}_{\mathrm{CO} 2}$ & - Carbon dioxide concentration in a gas mixture & {$[\% \mathrm{v} / \mathrm{v}]$ or $\left[\mathrm{mol}_{\mathrm{CO} 2} \cdot 10^{-2} \cdot \mathrm{mol}_{\mathrm{G}}^{-1}\right]$} \\
\hline $\mathrm{f}_{\mathrm{i}, \mathrm{N} 2}$ & $\begin{array}{l}\text { - Response factor of a mass-flow sensor for the ith gas } \\
\text { relative to nitrogen }\end{array}$ & {$\left[g_{i} \cdot g^{-1}{ }_{N 2}\right]$} \\
\hline$f_{k, N 2}$ & $\begin{array}{l}\text { - Response factor of a mass-flow sensor for the kth gas } \\
\text { relative to nitrogen }\end{array}$ & {$\left[g_{k} \cdot g^{-1} \mathrm{~N} 2\right]$} \\
\hline $\mathrm{G}_{\mathrm{m} 1}$ & - Gas mass-flow of the $1^{\text {st }}$ gas mixture & {$\left[\mathrm{g} \cdot \mathrm{min}^{-1}\right]$} \\
\hline $\mathrm{G}_{\mathrm{mij}}$ & $\begin{array}{l}\text { - Mass-flow rate of the ith gaseous component through } \\
\text { the jth mass-flow sensor or gas mixture }\end{array}$ & [g. $\left.\min ^{-1}\right]$ \\
\hline $\mathrm{G}_{\mathrm{mj}}$ & $\begin{array}{l}\text { - Mass-flow rate of a gas mixture through } \\
\text { the jth mass-flow sensor }\end{array}$ & {$\left[\mathrm{g} \cdot \mathrm{min}^{-1}\right]$} \\
\hline $\mathrm{G}_{\mathrm{miM}}$ & - Mass-flow rate of the ith component in the $\mathrm{M}^{\text {th }}$ a gas mixture & {$\left[\mathrm{g} \cdot \mathrm{min}^{-1}\right]$} \\
\hline $\mathrm{G}_{\mathrm{mM}}$ & - Mass-flow rate of of the $M^{\text {th }}$ gas mixture & {$\left[\mathrm{g} \cdot \mathrm{min}^{-1}\right]$} \\
\hline $\mathrm{G}_{\mathrm{mN} 2}$ & - Mass-flow-rate of nitrogen & {$\left[\right.$ g. $\left.\min ^{-1}\right]$} \\
\hline $\mathrm{G}_{\mathrm{v} 1}$ & - Volumetric gas flow rate of a gas mixture (Lpm) & {$\left[\right.$ L. $\left.\min ^{-1}\right]$} \\
\hline $\mathrm{G}_{\mathrm{vij}}$ & $\begin{array}{l}\text { - Volumetric gas flow rate of the ith gas component in } \\
\text { the jth gas mixture }\end{array}$ & {$\left[\right.$ L. $\left.\min ^{-1}\right]$} \\
\hline $\mathrm{G}_{\mathrm{vj}}$ & - Volumetric flow rate of the jth gas mixture & [L. $\left.\min ^{-1}\right]$ \\
\hline$M_{1}$ & - Molar weight of the gas mixture 1 (at the mixer inlet) & {$\left[\mathrm{g} \cdot \mathrm{mol}^{-1}\right]$} \\
\hline$M_{G}$ & - Molar weight of a gas mixture & {$\left[\mathrm{g} \cdot \mathrm{mol}^{-1}\right]$} \\
\hline$M_{i}$ & - Molar weight of the ith gas component & {$\left[\mathrm{g} \cdot \mathrm{mol}^{-1}\right]$} \\
\hline $\mathrm{N}$ & - Number of gases in a gas mixture & {$[-]$} \\
\hline$P$ & - Absolute pressure & {$[\mathrm{Pa}]$} \\
\hline $\mathrm{R}^{*}$ & - Perfect law gas constant $\left(=8,314 \mathrm{~J} \cdot \mathrm{mol}^{-1} \cdot \mathrm{K}^{-1}\right)$ & {$\left[\mathrm{J} \cdot \mathrm{mol}^{-1} \cdot \mathrm{K}^{-1}\right]$} \\
\hline $\mathrm{R}^{2}$ & - Correlation coefficient of a regression model & [ - ] \\
\hline $\mathrm{T}$ & - Absolute temperature & {$[\mathrm{K}]$} \\
\hline $\mathrm{t}$ & - Time & [min] \\
\hline V & - Sensor output voltage & {$[\mathrm{V}]$} \\
\hline Vol & - Gas volume & [L] \\
\hline$w_{i}$ & - Mass fraction of the ith gas component in a mixture & {$\left[g \cdot g^{-1}\right]$} \\
\hline$y_{i}$ & - Molar fraction of the ith gas component in a mixture & {$\left[\mathrm{mol} . \mathrm{mol}^{-1}\right]$} \\
\hline$y_{i j}$ & - Mole fraction of the ith gas component in the jth mixture & {$\left[\mathrm{mol} . \mathrm{mol}^{-1}\right]$} \\
\hline$\Phi_{\mathrm{M}, \mathrm{N} 2}$ & $\begin{array}{l}\text { - Response factor of the Mth gas mixture } \\
\text { relative to nitrogen of a gas mass-flow sensor }\end{array}$ & {$\left[g_{M} \cdot g^{-1} N 2\right]$} \\
\hline$\Phi_{\mathrm{M}, \mathrm{k}}$ & $\begin{array}{l}\text { - Response factor of the Mth gas mixture relative to the kth pure } \\
\text { gas or gas mixture of a gas mass-flow sensor }\end{array}$ & {$\left[g_{M} \cdot g^{-1} k\right]$} \\
\hline
\end{tabular}

\section{Subscripts}

i - with reference to the ith gas component of a mixture

j - with reference to the jth gas mixture or GMFM

M - with reference to the Mth gas mixture or GMFM

$\mathrm{G} \quad$ - with reference to a mixture of $\mathrm{N}$ gas components

N2 - nitrogen 


\section{Siglas}

GMFM - gas mass-flow meter

AirR - synthetic air

AirS - dried air

\section{REFERENCES}

[1] ISO 6145-7 (E), Gas analysis - Preparation of calibration gas mixtures using dynamic volumetric methods - Part 7: Thermal mass-flow controllers, $1^{\text {nd }}$ edition, ISO - International Organization for Standardization, Geneva, 2001.

[2] Li Qiu, Stefan Hein, Ernst Obermeier, Axel Schubert, Micro gas-flow sensor with integrated heat sink and flow guide, Sensors and Actuators, A 54 (1996) 547-551.

[3] ISO 6145-1 (E), Gas analysis - Preparation of calibration gas mixtures using dynamic volumetric methods - Part 1: Methods of calibration, $2^{\text {nd }}$ edition, ISO - International Organization for Standardization, Geneva, 2003.

[4] V. Ferreira, Desenvolvimento de um Sistema de Monitorização para um Processo de Compostagem, MSc. Thesis, University of Aveiro, Portugal, 2008.

[5] http://www.vaisala.com

[6] http://www.omron.com

[7] http://www51.honeywell.com/honeywell/ 


\section{BIOGRAPHY}

Manuel Arlindo Amador de MATOS (Env. Eng, MSc, PhD) is an Assistant Professor in Environmental Engineering, with research interests in thermochemical processes related with waste management.

Viviana da Silva FERREIRA (Env. Eng, MSc) is presently an Assistant Fellow in Environmental Engineering, and is developing her work in biological waste management processes. 